\title{
A SUB-REPRESENTATIVIDADE DE MULHERES NEGRAS E ORIENTAIS EM CAPAS DE REVISTAS BRASILEIRAS VOLTADAS AO PÚBLICO FEMININO
}

\author{
Marcel de Almeida Freitas ${ }^{1}$
}

Resumo:

O texto traz reflexões sobre alguns motivos culturais e mercadológicos para a quase nula presença de negras e orientais nas capas de revistas brasileiras voltadas para o público feminino. 0 artigo parte de um "mito" vigente na Publicidade segundo o qual "negro não vende" e, buscando desconstruir essa crença, apresenta uma enquete para averiguar se realmente o público feminino rechaça personalidades negras e orientais nas capas de revistas. Foram entrevistadas 100 universitárias da Universidade Federal de Minas Gerais e o resultado aponta que não há rejeição de personalidades orientais e negras nesta amostra em particular. Por fim, o texto cogita se não seriam as redações das grandes publicações que impõem modelos caucasianas atendendo a solicitações de mercado.

Palavras-chave: Revistas femininas; racismo; cultura de massa; estudantes universitárias.

\section{Abstract:}

The article brings reflections about some cultural and marketing reasons of almost absence of black and oriental women on the covers of Brazilian magazines directed to female readers. The paper come from a "myth" that exists in Brazilian Advertising field and, "black do not sell", and attempting to disassemble this belief, shows a survey to examine if really the female readings reject black and Asiatic people on the covers of the magazine. Were interviewed 100 female college students in the Universidade Federal de Minas Gerais and the result indicates that there is no rejection of Asiatic and black women in this specific sample. Finally, the text ponders if Caucasian models would be an imposition of main magazine redactors accomplishing marketing requirements.

Keywords: Female magazines; racism; mass media; female college students.

\section{Introdução}

Enquanto orientador de trabalhos interdisciplinares de conclusão de curso na área de Publicidade e Propaganda em uma instituição particular de ensino de Belo Horizonte fui percebendo um fato intrigante ao longo dos anos 2010: modelos ou atrizes negras e de origem oriental, mesmo que em algum papel de destaque na televisão, sistematicamente não apareciam nas capas de revistas, especialmente nas direcionadas ao público feminino.

Comparando tal fato às capas de revistas estrangeiras (quando a temática de alguma monografia que orientei tratava deste assunto) passei a questionar os motivos pelos quais sociedades com forte passado racista - como a alemã, por exemplo -

1 Prof. UEMG. Mestre em Psicologia Social (FAFICH/UFMG), Doutor em Educação (FaE/UFMG). Email: marcel.fae.ufmg@gmail.com 
proporcionalmente expõem mais mulheres não brancas em capas de mídia impressa que o Brasil, sociedade que, ao menos em se tratando do ideário que busca divulgar para o exterior, se mostra "orgulhosa" de sua (pretensa) "democracia racial". A fim de dirimir tais indagações, dei início a leituras e realizei uma sucinta coleta de dados quantitativos sobre o tema (entre julho e dezembro de 2017) que originaram este texto - mais provocativo e reflexivo que conclusivo.

\section{Questões metodológicas}

Os objetivos do texto são 1) provocar a reflexão sobre a quase ausência de mulheres negras e de origem asiática em capas de revistas brasileiras voltadas para o público feminino por meio de breve revisão da literatura sobre o tema; 2 ) verificar por intermédio de uma enquete quantitativa (não representativa, mas ilustrativa) com universitárias, se personalidade com esses biótipos não estampam capas de revistas no Brasil em razão de serem, inconscientemente, rechaçadas pelas leitoras e inferir, ao final, por meio de leituras de estudos específicos sobre essa temática 3) se seriam as redações das revistas que sistematicamente "evitariam" personalidades com tais origens étnicas e, mesmo inconscientemente, atribuiriam o motivo disso ao mercado consumidor.

Tais reflexões permitem entender melhor como a mídia cria referências sígnicas e padrões que invertem a realidade brasileira: a exceção se torna regra de beleza (mulheres louras, de olhos claros, magras e longilíneas) e se torna o referencial a ser (in)atingível para a maioria da população. Por meio dessas ilações vislumbra-se como muitos aspectos das relações étnicas e, secundariamente, de classe, pertinentes à cultura brasileira estão em operação na escolha e na produção das capas das revistas femininas e como tais diretrizes étnicas informam a cultura de massa, podendo ser interpretadas, em última instância, como uma forma de violência simbólica, como colocado por Pierre Bourdieu (2003).

Portanto, simbolicamente, a "capa" simboliza a "cara", a sala de visitas de uma revista. Outras pesquisas (BARBOSA; SILVA, 2009; BITTELBRUN, 2014) também vem apontando que a mídia impressa nacional ainda é resistente em estampar feições negroides e mongólicas em suas páginas. Propositalmente publicações étnicas como Raça e Made in Japan, direcionadas aos afrodescendentes e de origem japonesa, respectivamente, não foram apresentadas às entrevistadas da enquete, porque o alvo do artigo é verificar a 
presença de mulheres negras e orientais em revistas (que se dizem) voltadas para as brasileiras em geral.

Aqui a atriz Camila Pitanga não foi designada como negra, malgrado se identifique como tal, porque o que se considerou é o que o senso comum brasileiro identifica como "negra" (enquanto sinônimo de preto). Caso se procedesse com critérios similares aos norte-americanos, a atriz Juliana Paes, por exemplo, também seria "lida" como negra. Porém, como a cultura brasileira a vê como "morena" (parda), preferiu-se empregar o critério popular do que é e do que não é "preta" (LESSA, 2007). No caso do termo “oriental”, mesmo tendo nascido no Brasil indivíduos de ascendência japonesa, chinesa e coreana etc., recebem essa alcunha cotidianamente, por isso ainda que celebridades como Sabrina Sato e Daniele Suzuki sejam brasileiras de nascimento e de cultura, o artigo se referiu a elas como "orientais".

Em relação à coleta de dados, foram aplicados 100 questionários (abaixo descrito) a estudantes universitárias (de graduação ou pós) no universo constituído pela Universidade Federal de Minas Gerais. A aleatoriedade propiciada pelo local onde as estudantes foram abordadas $^{2}$ se encarregou de variar a amostragem em termos de classe social, curso, raça/cor e faixa etária. À discente era solicitado que indicasse, de próprio punho, uma única sugestão de capa para cada revista tendo em vista uma listagem de personalidades com diferentes fenótipos. A relação de celebridades femininas que lhes foi apresentada, nos termos étnico-raciais comumente utilizados nestas mesmas publicações, pode assim ser dividida:

Negras: 1. Sheron Menezes, 2. Taís Araújo; louras: 3. Adriane Galisteu, 4. Angélica, 5. Gisele Bündchen; morenas: 6. Camila Pitanga, 7. Carol Castro, 8. Fernanda Tavares, 9. Ivete Sangalo, 10. Juliana Paes, 11. Paula Fernandes, 12. Anitta; mediterrâneas (biótipo ítalo-ibérico): 13. Giovana Antonelli, 14. Luciana Gimenez, 15. Maureen Maggi; indígenas: 16. Caroline Ribeiro, 17. Dira Paes, 18. Luiza Brunet; orientais: 19. Daniele Suzuki e 20. Sabrina Sato. Na listagem elas apareciam em ordem alfabética. A seguir imagens destas mulheres em capas de revistas, algumas citadas na enquete. Propositalmente foram escolhidas mulheres de diferentes áreas de atuação pública (apresentadoras, cantoras, atrizes, modelos e uma atleta).

\footnotetext{
${ }^{2}$ Na Praça de Serviços do campus da UFMG, Pampulha, onde há grande circulação de pessoas da comunidade universitária em razão da concentração de bancos, lojas diversas e restaurantes.
} 
Figura 1. "Famosas" apresentadas às entrevistadas por ordem alfabética

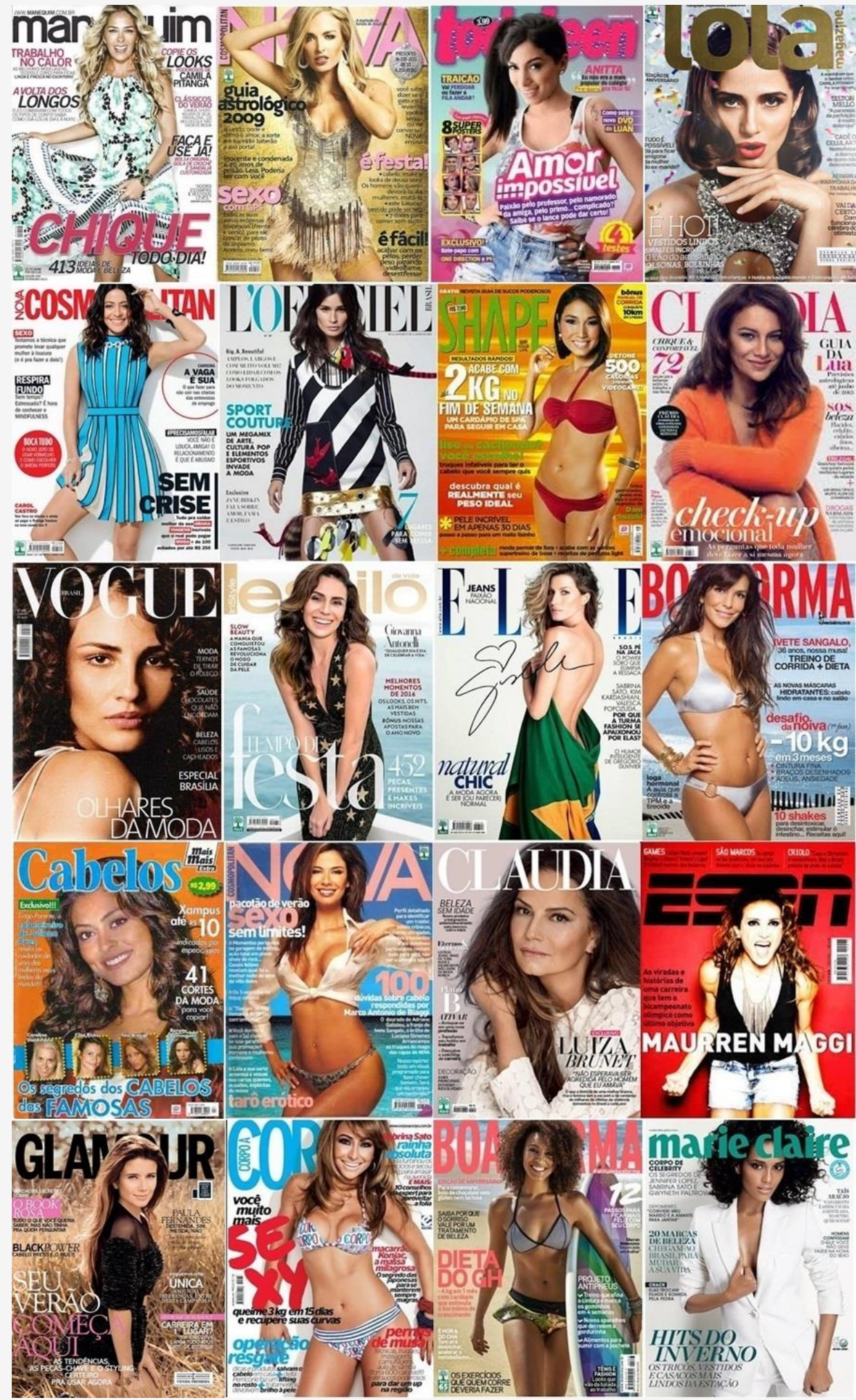

Fonte: $w w w . g o o g l e . c o m . b r / s e a r c h ? q=c a p a s+d e+r e v i s t a s+f e m i n i n a s \& s o u r c e=$ Inms\&tbm $=i s c h$ \&sa =X\&sqi=2\&ved=0ahUKEwiG6YDi9bjUAhWDQZAKHTK7AqcQ AUIBigB\&biw=1920\&bih=974 
A enquete foi feita com alunas que estavam sozinhas para que não houvesse opinião ou sugestão de colegas. O questionário, totalmente anônimo, foi apresentado conforme é exposto abaixo, considerando as publicações femininas de maior tiragem no país (ANER, 2018). Não foram apresentadas imagens das mulheres, apenas uma lista das mesmas em ordem alfabética, portanto, a menção dos nomes se deveu à "memória midiática" dos sujeitos.

Gostaria que você indicasse, considerando a listagens de mulheres em anexo, APENAS uma delas para ser CAPA de cada uma dessas revistas. Você pode repetir a personalidade, indicá-la para mais de uma publicação, mas para cada revista só pode citar UM nome. Obrigado.

Tabela 1. Listagem de publicações apresentada às entrevistadas

\begin{tabular}{|l|l|}
\hline \multicolumn{1}{|c|}{ Publicação } & \\
\hline Boa Forma & \\
\hline Capricho & \\
\hline Claudia & \\
\hline Corpo a Corpo & \\
\hline Cosmopolitan & \\
\hline Elle & \\
\hline Estilo & \\
\hline Glamour & \\
\hline Manequim & \\
\hline Marie Claire & \\
\hline Todateen & \\
\hline Vogue & \\
\hline
\end{tabular}

Curso: Idade: Estado Civil: 
Grosso modo, as revistas direcionadas para o público feminino indicadas podem assim ser separadas conforme a fatia de mercado que buscam contemplar e os conteúdos que veiculam: alta costura, viagens, música, cinema, teatro, decoração: Elle, Vogue. Moda, roupas, vestuário: Estilo, Manequim. Beleza física e temáticas corporais: Boa Forma, Corpo a Corpo. Adolescência, comportamento e sexualidade juvenil: Capricho, Todateen. Dilemas da mulher adulta, profissão, sexualidade, família, feminismo: Claudia, Cosmopolitan, Marie Claire. Variedades (aborda um pouco de quase tudo): Glamour.

Estas publicações foram escolhidas pelo fato de, na ocasião em que foram iniciados as leituras sobre a referida temática e os primeiros esboços dos escritos os quais, por sua vez, levaram ao "insight" de se fazer uma enquete sobre o assunto (por volta de 2016), estas eram as revistas voltadas ao público feminino com maior tiragem de vendas segundo a ANER, Associação Nacional de Editores de Revistas. É interessante destacar que no momento em que este artigo é público, várias destas publicações se encontram extintas.

Como o objetivo principal do trabalho é averiguar a recusa ou não de mulheres negras e orientais nas capas de revistas femininas, na descrição das indicações das entrevistadas optou-se por enfocar apenas à posição (ou possível ausência) que as personalidades negras e orientais aparecessem em termos numéricos, ou seja, se foram as mais indicadas para cada revista, se apareceram em até $10^{\circ}$ lugar, ou se não foram citadas nenhuma vez. Como é descrito ao final do artigo, não houve essa última ocorrência, ou seja, para TODAS as revistas foram sugeridos nomes de mulheres orientais e negras.

\section{Identidade, discriminação étnico-racial e comunicação de massa}

A cultura de massa, enquanto produto da indústria cultural, busca impor certos padrões de comportamento como referenciais gerais de conduta e de normatização de valores e parâmetros estéticos. Com o capitalismo industrial, tais fenômenos se tornam, aos poucos, disponíveis para os processos de identificação e de constituição das identidades dos sujeitos (BARBOSA e SILVA, 2009). Nesse sentido, entronizar padrões estéticos inatingíveis, além de causar autoestranhamento (alienação em relação ao próprio corpo), gera sofrimento psíquico e banimento social daqueles que não se enquadram nos rígidos modelos. 
Desde que teve início a mídia impressa de grande circulação no país (década de 1940), no processo de elaboração das capas de revistas brasileiras direcionadas ao público feminino, na maior parte das vezes, a brasileira negra, parda, de descendência indígena ou asiática não se vê representada nas capas das principais publicações e, levada à se adequar ao padrão estético eurocêntrico, se torna consumidora voraz dos produtos e serviços ofertados internamente nessas revistas. Conforme Nilma Gomes (2017), a questão estética para as populações afro-brasileiras, especialmente para as mulheres, historicamente vem se mostrando como um espaço privilegiado de violência simbólica e de controle do corpo.

Segundo Morin (2002), a cultura de massa se revela como elemento identificatório porque fornece um conglomerado de símbolos, mitos, imagens e discursos relativos à vida concreta e à vida fictícia das pessoas, constituindo, nesse amálgama, uma estrutura de projeções e de introjeções de significados peculiares. Assim, a cultura de massa criada a partir dos insumos político-econômicos da indústria cultural - da qual as revistas para o público feminino são manifestações - elabora sistemas de identificação a partir da imagem pública de artistas, entronizando-os como se fossem deidades perfeitas que, portanto, se tornam referências estéticas e comportamentais. Nesta dinâmica, raramente mulheres negras e orientais são instituídas como tal, não obstante as críticas que se deva fazer a este processo em si, isto é, não se configuram como referência para as mulheres em geral e, o que é paradoxal, muitas vezes nem mesmo para outras mulheres orientais e negras consumidoras deste tipo de mass media.

Nesse contexto, as revistas endereçadas ao público feminino - por serem mecanismo de comunicação de massa - se caracterizam pela uniformidade das mensagens, recursos imagéticos similares, transmissão a milhares de pessoas ao mesmo tempo, unilateralidade dos caminhos comunicativos, quase nula possibilidade de resposta por parte do público leitor, ausência de igualdade no poder decisão do receptor e caráter altamente persuasivo das mensagens (MARTINS, 2007); deste modo, criam uma autoridade simbólica (ou seja, algo é "chique” porque a revista prescreveu), usando-a na divulgação de determinados comportamentos, valores, formas e signos.

Com efeito, Adorno e Horkheimer (1985) tecem forte crítica à indústria cultural já na década de 1940. Através das ilações dos autores, entende-se que as atuais "revistas femininas" são como "manuais" porque, entre outros motivos, oferecem às leitoras não somente a imagem de personalidades, mas seus estilos de vida em si mesmos. Dessa maneira, tais publicações contribuem para que o pensamento coletivo se torne obtuso e hegemônico, pois é da essência dos manuais conduzir às práticas sem reflexão, pois, todo 
receituário é, por definição, preceptivo. Entretanto, de acordo com Morin (2002), a cultura de massa não é exterior às demais (religiosa, esportiva, erudita, científica etc.), e retira desses outros discursos o material a ser "pasteurizado" e devolvido - simplificado - à sociedade. Por essa razão a mass culture se pretende universal, já que busca incorporar as subculturas.

Contraditoriamente, a indústria cultural que surgiu a partir da moderna sociedade industrial capitalista, valorizando a individualidade do sujeito, o faz "por atacado", conduzindo à massificação da personalização: todos são obrigados a ser únicos, e só o serão usando as mesmas roupas, os mesmos cortes de cabelos, lendo as mesmas revistas. Na sociedade moderna, esses padrões de consumo se tornam como que uma língua comum, um dos poucos fenômenos que congrega grandes quantidades de pessoas na atualidade. Tais modos culturais criam relativa "afinidade" entre os inúmeros desagregados dos sistemas tradicionais, que buscam aplacar as angústias decorrentes da extrema individualização e fluidez das relações através do consumo exacerbado.

O desiderato da homogeneização dos comportamentos femininos, expresso nas revistas voltadas para esse segmento, faz parte das práticas do marketing de massificar ao máximo o mercado, porque seu êxito depende da existência de uma conformação acrítica por parte dos diferentes tipos de mulheres que, assim, passam a se referenciar no mesmo conjunto de produtos da indústria cultural, consumindo-os vorazmente (BARBOSA; SILVA, 2009). Apesar disso, as consumidoras de revistas se encontram divididas por uma relativa segmentação de mercado, em geral classificada por classe social e por faixa etária.

Alguns exemplos de publicações brasileiras com perfis típicos de leitoras seriam as revistas Cláudia, voltada para mulheres das classes A e B, casadas, geralmente com filhos de até 15 anos e Capricho, direcionada para adolescentes das classes A, B e C com até 20 anos. Isso só pôde acontecer, de acordo com Flor (2009), a partir da década de 1960, quando o parque industrial brasileiro se modernizou e o meio editorial passou a contar com maquinário de ponta. Não por acaso, estas duas revistas voltadas para mulheres estão entre as mais antigas no mercado editorial brasileiro.

Daí em diante a mídia impressa passou, permanentemente, a ser encarada como um forte produto comercial. As primeiras revistas femininas a aparecerem no Brasil foram as da Editora Abril: Fotonovelas, Agulha de Ouro, Bom Apetite, Manequim, Casa Cláudia, Cláudia. Na representação social dos anos 1950 os assuntos que interessariam às mulheres eram: novelas, corte e costura, culinária, moda, decoração, relacionamento com o parceiro e educação dos filhos. Tais temas eram postos como referências para a identidade 
social e para o comportamento individual das mulheres da época. Não obstante a multiplicidade de assuntos direcionados ao público feminino hoje, essas pautas tradicionalmente vêm sendo ofertadas às mulheres até o presente nas publicações, que se pretendem fontes seguras de informação (isto é, não assumem e/ou enxergam seu caráter prescritivo e impositivo).

As peças publicitárias e matérias dessas revistas são bem direcionadas para certo público; desse modo, as revistas induzem à imitação inconsciente de certos padrões de feminilidade, fenômeno psicossocial alicerçado no consumo e na aquisição de artefatos simbólicos. Segundo Morin (2002), dessa forma, a cultura de massa busca a integração de temáticas do universo feminino em conteúdos altamente padronizados e os oferecem "em kits". Contribuindo para a consolidação de determinados padrões de gosto, as revistas alimentam um círculo que nutre a si mesmo, posto que, com os mesmos desejos as leitoras consumirão e se comportarão de modos similares, recorrendo aos anunciantes das revistas para ficaram "in" e para saciarem seus desejos que, elas acreditam, são exclusivamente delas e baseados em liberdade de escolha.

Com efeito, os meios de comunicação e a publicidade em especial - o cerne financeiro das revistas - lidam com a perspectiva racial de modo ainda obsoleto. Para Martins (2007), “[...] o negro ainda é visto pelo viés dos estereótipos [...]. Poucas vezes é retratado de forma positiva”. Em geral o homem negro é caracterizado como jogador de futebol e a mulher negra como dançarina/passista de samba. Não são enxergadas outras potencialidades: cientistas, profissionais liberais, cidadãos, políticos, religiosos etc. Tendo isso em conta, é urgente que a mídia impressa comece a questionar suas práticas de trabalho e o caráter ético de suas produções. Tal responsabilidade social é importante porque, conforme Corrêa (2006), o tratamento preconceituoso que a mídia vem dedicando ao negro influencia o cotidiano das pessoas. Um dos efeitos desse processo é a autodepreciação.

O preconceito contra o negro vem acompanhado de outros: contra o nordestino, as classes populares, mulheres, asiáticos. Outro fator é que tanto nas revistas quanto na publicidade o que é produzido no eixo Rio-São Paulo é o que caracteriza a comunicação de massa em todo o Brasil. Mesmo nas produções regionais, o indivíduo negro raramente aparece, isso porque o olhar que se tem dele é dado pelo Sudeste, o dominado se vê com as categorias cognitivas do dominador. O povo brasileiro não é retratado em sua multiplicidade e nuanças nas produções midiáticas. A mesma autora também diz que não se resolve tal questão colocando mais afrodescendentes nas linhas de produção das 
redações e/ou das agências publicitárias, pois se estes tiverem uma visão eurocêntrica do mundo e das artes, reproduzirão os mesmos modelos que thes foram ensinados como válidos. Nesse sentido,

\begin{abstract}
A hierarquização se dá de forma muito penosa para o elemento negro. 0 sujeito quando chega à redação acaba incorporando o branqueamento. Ele não traz para o cotidiano da redação as discussões de sua realidade. É como a mulher, quando chega ao cargo de gerenciamento acaba ficando tão fálica quanto o homem, (...), é preciso haver uma desconstrução (MARTINS, 2007).
\end{abstract}

Dessa maneira, mesmo se a lei proposta pelo Senador Paulo Paim fosse aprovada garantindo cota de participação de afrodescendentes nas campanhas publicitárias, só isso não resolveria o problema, já que o consumidor, individualmente, e o mercado, como um todo, não se reconhecem nessa categoria. Por outro lado, num país tão miscigenado como - Brasil, cotas para afrodescendentes sozinhas não solucionam o problema de exclusão estética daqueles que "visivelmente" no Brasil são classificados como negros - os pretos, pois uma loura de olhos azuis, como a atriz Grazy Massafera ${ }^{3}$, por exemplo, iria continuar estampando mais capas de revista e campanhas que a Taís Araújo, por exemplo, já que a exigência é por afrodescendentes na mídia, e não por "pretos", desse modo, o veículo em questão não poderia ser acusado de não estar cumprindo a cota. 0 que permaneceria acontecendo é que “[...] a produção e recepção de personagens negros na publicidade existem muito mais para suprir interesses institucionais (como mais uma ação para demonstração de responsabilidade social) do que para inseri-lo na sociedade" (MARTINS, 2007).

De fato, o debate ultrapassa a simples obrigação legal de haver modelos negros nas campanhas publicitárias e em capas de revistas. 0 que urge é sua incorporação ao contexto das peças, enquanto protagonistas. Frequentemente o negro aparece como caricatura, folclorizado, exótico ou meramente decorativo (num editorial de moda que tem o safári como temática, por exemplo, ele não é o modelo que usa a roupa, mas é o africano auxiliar do caçador). Logo, sua presença é sempre "avulsa” na peça, sem identidade. A questão não é apenas estar presente, mas sim atuar, não ser um adereço em uma

\footnotetext{
3 Em entrevista ao programa TV Fama da Rede TV em 2015, a ex-Big Brother e atual atriz paranaense respondeu, quando questionada sobre o "exotismo" da sua beleza, traços fortes, pele "naturalmente bronzeada", cabelos e olhos claros, que "achava" que adviria do fato de sua mãe ser de origem polonesa e indígena e seu pai de origem negra e italiana. Nestes termos, no sistema classificatório "de sangue", prevalente nos Estados Unidos por exemplo, Grazy Massafera seria negra, ainda que não seja preta.
} 
campanha. Isso se dá porque a prática comum no campo publicitário é a de colocar um negro ou outro de forma compulsória como se, para ser “moderna”, uma peça publicitária tivesse que contar com exóticos que não são exatamente os protagonistas do mercado.

Outro momento em que o negro aparece na publicidade, também extra cotidiano, é o das campanhas governamentais, de ONGs etc. Aqui ele é trazido como representante das camadas "carentes" da população, como o indivíduo que foi beneficiado por alguma filantropia privada ou por serviço público (MARTINS, 2007). Para o campo comunicacional brasileiro, a figura do negro não transmitiria conceitos como refinamento e sofisticação, portanto, a publicidade "transfere" para o público consumidor parte da responsabilidade pela ausência de negros na mídia, ou seja, seriam os receptores que o rejeitariam.

Todavia, o lado comercial seria uma "desculpa" para a incapacidade e/ou animosidade por inovação dos padrões estéticos em voga, que advém do preconceito impregnado na mentalidade dos próprios profissionais em comunicação, que não conseguem conceber que pessoas negras também podem transmitir valores e conceitos nobres e belos. Com isso,

O mercado publicitário transfere a culpa para o consumidor que, segundo ele, não gosta de ver o afrodescendente na mídia, mas ele mesmo não tem como se esquivar e se inocentar do fato de não ousar mudar, criar outro público (ARAÚJO, apud MARTINS, 2007).

Consequentemente, essa postura do campo midiático, que se recusa a afrontar uma cultura conservadora (classista, machista e racista) alimenta, endossa e propaga representações sociais discriminatórias. A identidade negra no Brasil não nasceu de uma recente conscientização a respeito de distinções biológicas entre grupos de pessoas negras e brancas ou negras e amarelas; é produto de um extenso e demorado processo histórico que tem início da colonização do continente africano no século XV e do contato com seus habitantes por parte dos conquistadores portugueses (MUNANGA, 1988). Tal processo desencadeou relações mercantilistas com a África, o tráfico negreiro e o submetimento dos povos africanos. Foi aí que começou a gestação da identidade afro-brasileira.

No caso dos negros no Brasil, tais construções simbólicas foram, pouco a pouco, formando uma identidade negativa que inicialmente era atribuída, mas que, com o passar dos séculos, foi internalizada pelas próprias vítimas do preconceito racial. No contexto nacional, tais questões se chocam com outro fenômeno inegável da sociedade brasileira: a miscigenação. Portanto, a afirmação ou negação de uma identidade negra só consegue ser 
compreendida, no Brasil, dentro do quadro de construção da identidade brasileira que sempre "[...] quis assimilar os africanos e seus descendentes brasileiros numa cultura considerada como superior. Assimilação essa que se faria através da falsa mestiçagem cultural e da miscigenação" (MUNANGA, 1988, p. 33).

Por essa razão, a dinâmica da construção das identidades não permite pensá-las enquanto essência, mas como fruto de determinadas circunstâncias histórico-culturais. Todo preconceito trata a diferença - classe, raça, gênero, sexualidade, faixa etária - de forma pejorativa, como se fosse pior/menor. No caso da questão étnico-racial, fomentam o surgimento de pensamentos e/ou comportamentos etnocêntricos, tais como o ora estudado: a exclusão sistemática das mulheres negras e orientais das capas de revistas endereçadas a mulheres. Esse fenômeno midiático isolado é irrelevante, porém, deve ser interpretado como elemento de um sistema social racista amplo e sinaliza, ainda que não intencionalmente, a permanência de "[...] uma auto-depreciação que hoje se tornou uma das armas mais eficazes de sua própria opressão" (MUNANGA, 1988, p. 47).

Dessa maneira, a falta de reconhecimento midiático da mulher negra, por exemplo, cuja ilustração é a recusa em expô-la nas capas das revistas, desvela não somente que pessoas portadoras dessa identidade racial-cultural não têm visibilidade, mas instaura uma ruptura na autoimagem desses sujeitos, que não possuem muitos modelos positivos em quem se mirar. Assim, considerando que não estar na capa de uma revista de relevância no mercado editorial é sinal do não reconhecimento de certo tipo físico (oriental, negro, ruivo etc.) enquanto representante estético, “[...] o reconhecimento não é apenas uma cortesia que se faz a uma pessoa: é uma necessidade humana” (MUNANGA, 1988, p. 49). Tal estratégia não é nova: desde o começo do processo colonizador os europeus impuseram imagens negativas aos dominados acerca de si próprios afim de desmontar sua cultura, religiosidade e padrões estéticos e substituí-los pelos valores e práticas europeus.

\section{Descrição e análise dos dados coligidos}

A amostra de 100 estudantes foi aleatória simples e o critério para que a pessoa fosse abordada era estar só (estudando, lanchando, usando celular etc.) para que não houvesse interferência de terceiros. Em função do tamanho reduzido da amostra (não é representativa, mas sim ilustrativa), os cursos de engenharia foram agregados sob a mesma rubrica. A amostra assim se distribuiu: Medicina (8\%), Pedagogia e Direito (7\% cada), 
Administração, Enfermagem, Letras e Engenharias (6\% cada), Comunicação Social, Veterinária e Odontologia ( $5 \%$ cada), Fisioterapia (4\%), Sistema de Informação, Educação Física, Psicologia, Ciências Contábeis, Geografia e Farmácia (3\% cada), Biblioteconomia, Biomedicina, Economia, Geologia, Terapia Ocupacional e Arquitetura (2\% cada), Turismo, Química, Ciências Biológicas, Nutrição e Belas Artes (1\% cada). Estado Civil: 85\% solteiras, $9 \%$ casadas, $2 \%$ separadas, $4 \%$ outras situações. Faixa etária: $60 \%$ têm até 32 anos.

A fim de não se estender em demasia o texto e como o intuito do trabalho não era propriamente sobre as revistas em si mesmas, mas sobre a possível rejeição de mulheres dessas origens étnico-raciais nas capas, abaixo se descreve apenas se mulheres orientais e negras apareceram e em que posição (de $1^{\circ}$ a $10^{\circ}$ ) para cada uma das publicações apresentadas para as entrevistadas.

Boa Forma: A segunda mulher mais citada para sua capa foi uma negra que, curiosamente, nunca foi capa da publicação até então (Sheron Menezes, mas que, coincidentemente, o fora meses depois) e o primeiro ficou com uma atriz considerada pelo senso comum como a típica miscigenação de brancos, negros e índios, Juliana Paes.

Capricho: Os valores da revista Capricho são semelhantes aqueles encontrados na outra revista voltada para o público adolescente, Todateen, se destacando em ambas revistas a posição proeminente das duas orientais: Daniele Suzuki e Sabrina Sato. Também foram indicadas para essa capa as duas mulheres afrodescendentes entre as dez mais citadas.

Cláudia: A paraense Dira Paes, de explícito biótipo indígena, foi a terceira mais citada. Curioso constatar que as únicas três mulheres não citadas entre as dez primeiras indicações pertencem às etnias foco do estudo, as duas orientais e uma das duas negras (Sheron Menezes), porém, esse fato estaria mais ligado ao perfil etário da leitora de Cláudia - madura, casada, com filhos - do que à questão racial. Tal ilação é confirmada pelo fato de estas mulheres aparecem com alta frequência em praticamente todas as outras indicações, inclusive para revistas voltadas ao público teen, isto é, certamente não se trata de um rechaço específico à etnia/cor dessas mulheres.

Corpo a Corpo: Por meio das menções pode-se observar que, para a mulher brasileira em geral, o padrão longilíneo das top models não é tido como ideal absoluto de beleza corporal, sendo preterido em relação à mulher "sarada": Juliana Paes ou Ivete Sangalo, por exemplo. Concernente ao tema racial, Taís Araújo está entre as dez mais mencionadas. 
Elle: Até então (2017) a única capa que tal publicação havia feito com uma personalidade negra foi logo após sua chegada ao Brasil (em 1988), no início da década de 1990. Mesmo assim, a modelo não era brasileira. Em relação às asiáticas, nenhuma foi contemplada com capa até hoje. Sobre os números para essa revista a distribuição de orientais e negras foi a seguinte: Sabrina Sato em quinto lugar, Taís Araújo em décimo e Sheron Menezes em vigésimo. Daniele Suzuki não foi sugerida para a capa, por certo, novamente o motivo não seria racial, mas sim ao perfil midiático ainda associado à adolescência da atriz.

Estilo: As cinco primeiras posições dessa publicação foram bem diversificadas em termos étnicos, sendo que o primeiro lugar foi ocupado por uma mulher que, não obstante se identifique como negra, em termos do senso comum seria a tradicional mescla brasileira: Camila Pitanga. Taís Araújo, ficou em quarto lugar. Daniele Suzuki, que não foi capa da publicação até o momento, foi sugerida na $16^{a}$ posição. Sabrina Sato, que já apareceu na capa algumas vezes, não foi mencionada.

Glamour: O primeiro lugar em sugestões ficou com uma negra (Taís Araújo) e, talvez pelo fato de não ter fixidez em relação à faixa etária, perfil de classe ou temática, a distribuição percentual para esta revista mostrou-se como excelente "categoria teste" para a técnica utilizada na coleta de dados, ou seja, apontou se os sujeitos da pesquisa responderam conscientemente ao questionário.

Manequim: as duas asiáticas - Daniele Suzuki e Sabrina Sato foram mencionadas, bem como as duas negras - Sheron Menezes e Tais Araújo, não obstante, apenas Sabrina Sato e Taís Araújo estiveram na capa desta publicação até o momento. Vale notar também que todas as quatro ficaram depois da décima posição em citações. Os nomes mais indicados foram de top models (Gisele Bundchen, Caroline Ribeiro, Fernanda, Tavares, Luiza Brunet), imageticamente mais associadas ao universo da moda e dos vestuários em geral.

Marie Claire: nessa publicação que se propõe o slogan "chique é ser inteligente", somente Sabrina Sato e Sheron Menezes não apareceram entre as orientais e negras citadas pelas estudantes, porém, Sabrina Sato, diferentemente de Sheron, foi capa dessa publicação por quatro vezes, a única oriental a ser capa da publicação até agora. 0 interessante dessa ocorrência é que Sabrina trabalha como apresentadora na Rede Record, concorrente ao grupo ao qual pertence a revista Marie Claire, Organizações Globo. Taís Araújo e Daniele Suzuki foram bem cotadas para a capa, no entanto, não ficaram entre as cinco mais sugeridas. 
Figura 2. Revista Marie Claire de out/2013 com Sabrina Sato na capa

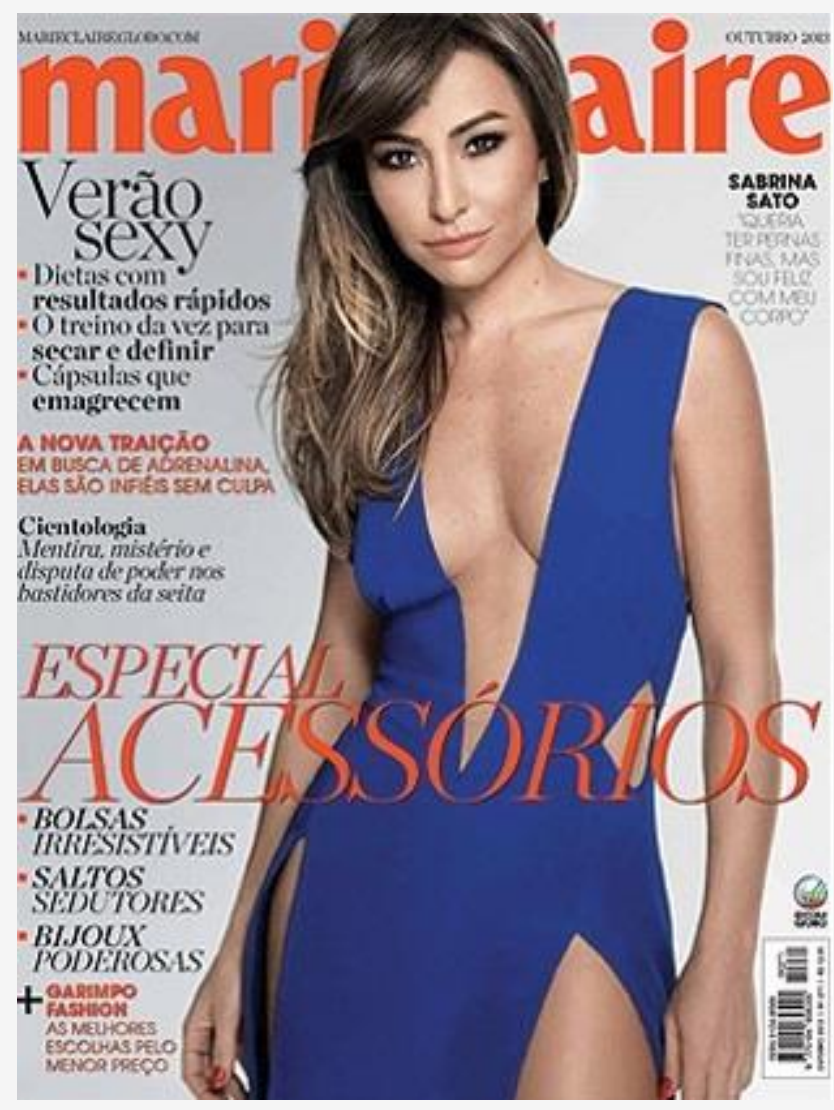

Fonte: http://revistamarieclaire.globo.com/

Nova: a partir de 2015 passou a se chamar Cosmopolitan como as versões internacionais. Em relação às orientais e negras, era, até pouco tempo, uma das publicações mais resistentes a colocar mulheres dessas etnias em sua capa, quiçá por vetos de ordem mercadológica, ou seja, anunciantes, baseados em estudos desatualizados, ainda acreditassem que "negro não vende" (CORRÊA, 2006), opondo-se, ainda que indiretamente, a publicação de fazer capas com negras como, por exemplo, Taís Araújo que, coincidentemente, foi o primeiro lugar em menção para essa revista. Um adendo: até janeiro de 2010 Taís Araújo (então protagonista de uma novela das $21 \mathrm{hs}$ ) havia sido a segunda negra na capa da revista; a primeira fora uma modelo norte-americana, em 1977, logo depois que a publicação chegou ao Brasil. Sheron Menezes e as duas orientais também foram indicadas para a capa. 
Figura 3. Revista Nova de jan/2010 com Taís Araújo na capa

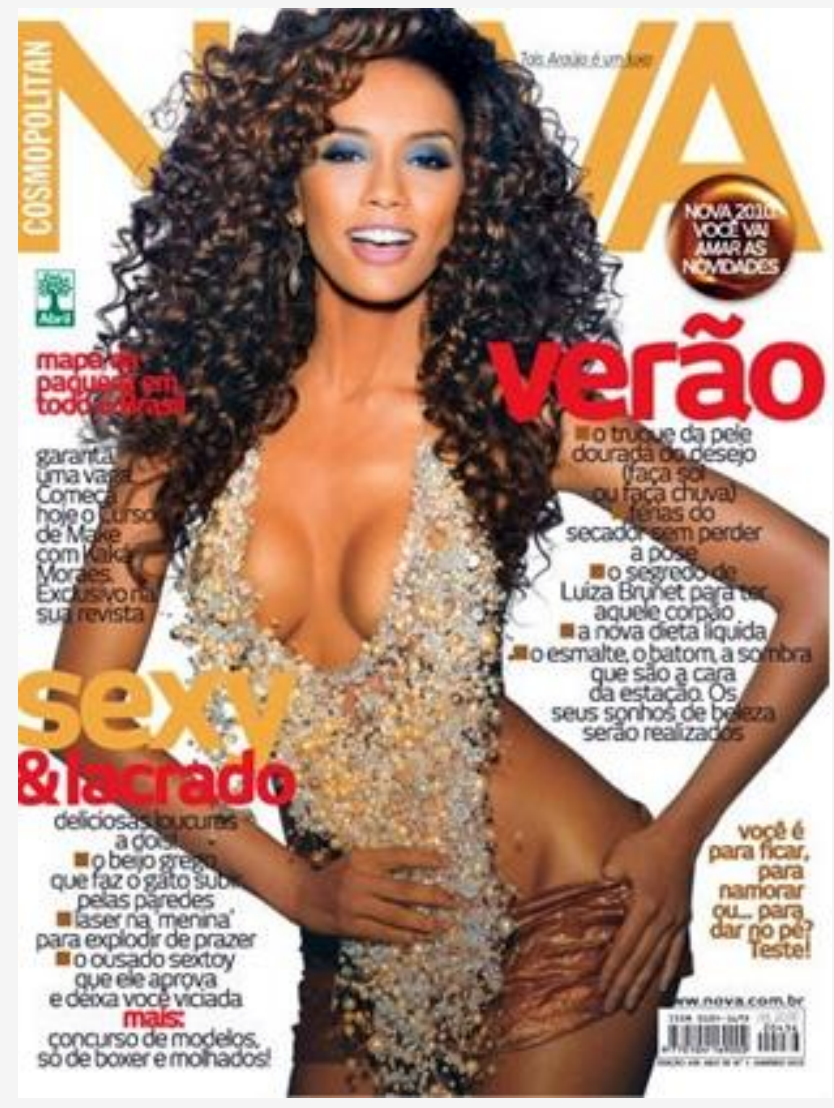

Fonte: http://nova.abril.com.br/

Todateen: Os três primeiros lugares (Daniele Suzuki, Sheron Menezes e Sabrina Sato) evidenciam que, para estas universitárias, critérios étnico-raciais são irrelevantes quando se trata de associar alguém à capa de uma revista, sendo mais importante, para tal vinculação, a faixa etária, a personagem que a atriz interpreta no momento ou aspectos de sua vida pessoal.

Vogue: Revista voltada para o mundo da alta costura, para o chamado high society e da moda sofisticada, Gisele Bundchen, como já se presumia, foi a celebridade mais indicada para a capa. Entretanto, algumas surpresas se fizeram presentes, como a sugestão de Sheron Menezes, personalidade negra associada à personagens “populares" na televisão e sem midiática vinculação ao consumo de luxo. Possivelmente em função do tipo de programa que apresenta, popular e até caricatural, Sabrina Sato não foi sugerida para essa capa, ao passo que a atriz Daniele Suzuki sim, bem como Taís Araújo. 


\section{Considerações finais}

Em razão do ideário coletivo discorrido e tendo-se em vista a composição da população brasileira, não obstante as controversas classificações oficiais, tanto orientais quanto negras são ainda sub-representadas nas capas de revistas do Brasil, fenômeno midiático que vem sendo estudado mais recentemente (LEVY, 2015). Todavia, considerando que o percentual de asiáticos é assaz menor que o de negros na composição étnico-racial do brasileiro e que a concentração dos imigrantes dessa origem se deu basicamente nos estados de São Paulo e Paraná, mulheres orientais estão mais bem representadas que as negras. Ademais, observando que a inserção da mulher asiática na mídia é recente - tendo começado mais fortemente a partir da participação de Sabrina Sato no programa Big Brother - a comparação é ainda mais desfavorável em relação às mulheres negras.

Segundo a literatura consultada, o perfil geral das revistas que mais frequentemente expõem negras em suas capas se caracteriza por se concentrar em revistas populares ou então em revistas de vanguarda ${ }^{4}$ dirigidas às classes altas e voltadas ao restrito mundo da arte e da alta costura (BITTELBRUN, 2016). Ainda, não foram encontrados estudos brasileiros que versam sobre os valores, símbolos ou mesmo a frequência numérica de mulheres de origem oriental em capas de revista ou na publicidade brasileira, daí que este artigo sugere investigações neste sentido.

A breve enquete realizada ajuda a desconstruir a "desculpa" de que "negro não sai em capa de revista porque não vende", mito este já investigado em diversos estudos sobre a ausência de negrxs no campo publicitário impresso (CORRÊA, 2006). Se isso foi uma verdade num passado recente da mídia impressa, faz-se imperioso que essa mídia acompanhe a mídia televisiva e a virtual, entre outras modalidades, abandonando arcaicos padrões de produção e, principalmente, que não a use como "escudo" para possíveis preconceitos de diretores de redação, publicitários, anunciantes e redatores o que hoje, provavelmente, seria o que ainda veta celebridades negras e orientais nas capas das revistas.

Em síntese, enquanto que na televisão brasileira a presença de negros em geral e, dentro dessa categoria, as mulheres negras, se multiplicou em número e se diversificou no que concerne aos perfis de personagens (rica, pobre, patroa, empregada, vilã,

\footnotetext{
4 Ambos extremos não abordados nesse artigo, pois muito específicas e com isso se corria o risco de as estudantes não conhecerem estas publicações.
} 
protagonista etc.), saindo do clichê doméstica/escrava, a mídia impressa não acompanha tal evolução, ainda há uma subutilização de modelos, atrizes e personalidades nas capas de revistas. Dizendo de outro modo: a participação de mulheres negras em publicações não específicas para os afrodescendentes ainda está aquém de sua fatia de mercado enquanto consumidoras e da visibilidade que vieram adquirindo lentamente na televisão brasileira e, sobretudo, do percentual demográfico que representam na população brasileira.

No caso das mulheres orientais, elas também aparecem muito pouco em revistas para o público em geral, no entanto, de acordo com Lévy (2015), a estas não são associados valores simbólicos negativos como delinquência ou ausência de refinamento, e a justificativa da mídia impressa para esta ausência é a questão demográfica, isto é, ao fato de existirem poucas mulheres com essa ascendência na população brasileira como um todo. Porém, cabe finalizar que tanto as duas mulheres com essa origem étnica quanto as duas negras não foram rechaçadas como sugestão de capas por parte das 100 universitárias entrevistadas em nenhuma das doze publicações.

\section{Referências}

ADORNO, T. W.; HORKHEIMER, M. Dialética do Esclarecimento: fragmentos filosóficos. Rio de Janeiro: Jorge Zahar, 1985.

ANER. Associação Nacional de Editores de Revistas. Disponível em: https://www.aner.org.br/. Acesso em: 22/07/2017.

BARBOSA, E. G.; SILVA, S. A. B. Mulheres Invisíveis: a imagem da mulher negra no jornalismo de revista feminino brasileiro. Cambiassu, São Luís, n. 5, v.1, 2009, p. 48-68.

BITTELBRUN, G. V. As negras de 'Cláudia', luso-tropicalismo em revista. Revista Científica Ciência em Curso, Palhoça, n. 2, v. 3, jul/dez. 2014, p. 157-165.

BITTELBRUN, G. V. A negra que não está na capa de revista: debates sobre raça e gênero. Anuário de Literatura, Florianópolis, v. 21, n. 1, 2016, p. 170-187.

BOURDIEU, P. O poder simbólico. 6 ed. Rio de Janeiro: Bertrand Brasil, 2003.

CORRÊA, L. G. De corpo presente: o negro na publicidade em revista. Dissertação de Mestrado. Belo Horizonte: FAFICH/UFMG, 2006. 
FLOR, G. Corpo, mídia e status social: reflexões sobre os padrões de beleza. Revista de Estudos em Comunicação, Curitiba, v. 10, n. 23, p. 267-274, set-dez/2009.

GOMES, N. Movimento Negro Educador: saberes construídos nas lutas por emancipação. Petrópolis: Vozes, 2017.

IKEDA, F. S. M. O mito na mídia: um sistema semiológico dependente. Temática, João Pessoa, ano XI, n. 11, nov./2015, p. 40-51.

LESSA. O Brasil não é bicolor. In: FRY, P.; MAGGIE, Y.; MONTEIRO, S.; SANTOS, R. V. Divisões Perigosas: políticas raciais no Brasil contemporâneo. Rio de Janeiro: Civilização Brasileira, 2007.

LEVY, N. A mídia e autoestima das mulheres negras. Blog Tinha que Ser Mulher, 19 setembro, 2015. Disponível em <http://tinhaquesermulher.com.br/a-representatividadedas-mulheres-negras-na-moda/>. Acesso em: 10/01/2017.

MARTINS, S. Mídia trata relações raciais de forma preconceituosa. Observatório da Imprensa. 16/01/2007. Disponível em: <www.observatoriodaimprensa.com.br>. Acessado em 30/09/2008.

MORIN, E. Cultura de Massas no Século XX: neurose. Rio de Janeiro: Forense, 2002.

PENNAFORT, R. Mercado editorial apresenta quedas. O Estado de S. Paulo, 15/12/2016. Disponível em: <http://cultura.estadao.com.br/noticias/literatura,mercado-editorialapresenta-quedas, 10000094894>. Acesso em: 12/03/2017.

MUNANGA, K. Uma abordagem das noções de raça, racismo, identidade e etnia. Estudos \& Pesquisas, Niterói, n. 4, p. 43-65, 1998.

SANTOS, W. O.; SILVA, P. V. B. Racismo Discursivo e a Mulher Negra: análise a partir dos personagens presentes na publicidade. Revista Theomai, Buenos Aires, n. 21, p. 161-169, $1 \% / 2010$. 


\section{Como citar este artigo}

FREITAS, Marcel de Almeida. A sub-representatividade de mulheres negras e orientais em capas de revistas brasileiras voltadas ao público feminino. Revista Dispositiva. [on-line] Disponível em: <http://periodicos.pucminas.br/index.php/dispositiva> Editor Responsável: Conrado Moreira Mendes. Volume 9, Número 15, Belo Horizonte, julho de 2020, p. 174-193. Acesso em "dia/mês/ano".

Texto recebido em: 01/09/2017

Texto aprovado em: 13/09/2019 